\title{
ME VOY A ESPAÑA A TRABAJAR... FAMILIAS MIGRANTES COLOMBIANAS, REMESAS ECONÓMICAS Y RELACIONES DE GÉNERO EN UN CONTEXTO TRANSNACIONAL
}

\author{
“I'M OFF TO WORK IN SPAIN”. COLOMBIAN MIGRATING FAMILIES, \\ ECONOMIC REMITTANCES, AND GENDER RELATIONS IN A TRANSNATIONAL \\ CONTEXT
}

Marcela Tapia Ladino ${ }^{1}$ y Herminia Gonzálvez Torralbo ${ }^{2,3}$

\begin{abstract}
Basándose en una etnografía multisituada sobre familias migrantes colombianas, las autoras examinan las transformaciones y permanencias en las relaciones y prácticas de género como producto del impacto de las remesas económicas en un contexto transnacional. La tipología familiar es un elemento central para dimensionar dicho impacto, puesto que se aprecia un mayor fortalecimiento de la autoestima y una satisfacción de logro en las familias monoparentales con jefatura femenina. Si bien las remesas no modifican las relaciones de género se observa un impacto en la valoración de las familias, especialmente respecto de las mujeres migrantes.
\end{abstract}

Palabras claves: familias migrantes, transnacionalismo, remesas, género, colombianos.

Based on a multi-sited ethnographic study of Colombian migrant families, the authors examine the transformations and continuities of gender relations and practices, as a result of the impact of remittances, in a transnational context. Family typologies are an important element in determining this impact because improvements in self-esteem, as well as satisfaction regarding achievements, are more commonly found in single-parent families with female heads. Even if remittances do not altergender relations, they do have impacts on families' appreciation of migrant women, and especially on how they conceive of themselves.

Key words: Migrant families, transnationalism, remittances, gender, Colombians.

La conversión de España en un país de destino migratorio desde fines del siglo XX hasta la reciente crisis, ha provocado una creciente preocupación por parte de los investigadores de las ciencias sociales (Aurabell 2000; Bardají 2006; Juliano y Provansal 2008). La situación ha dejado en evidencia la multidimensionalidad del fenómeno y el impacto del boom migratorio en el país de origen y en el de destino $^{2}$. Dentro de la vasta producción investigativa, aquella que relaciona remesas, migración y género ha sido uno de los ámbitos menos explorados. En este contexto, el objetivo de este artículo es analizar la influencia de las remesas económicas en los procesos de transformación y permanencia de las relaciones y prácticas de género al interior de las familias transnacionales colombianas. Este objetivo se enmarca en un proyecto de investigación más amplio que persiguió indagar por el impacto de las remesas económicas y sociales en las relaciones familiares y de género. Los sujetos de referencia del presente trabajo fueron familias colombianas formadas en un contexto transnacional que conectan el Área Metropolitana Valle de Aburrá (AMVA) y el Área Metropolitana Centro Occidente (AMCO), en Colombia, con Medellín y Pereira como ciudades protagonistas respectivamente con la Comunidad de Madrid, en España. La relevancia de la investigación se relaciona con la vinculación de dos zonas colombianas de mayor salida de población y la Comunidad madrileña, que ha sido una de las capitales europeas de mayor recepción de inmigrantes provenientes de América Latina antes de la crisis que se inicia en el $2008^{3}$.

En el caso que nos ocupa más que establecer la magnitud, periodicidad o administración de las remesas en términos económicos, interesa atender a los procesos que se desatan con el uso de dichos recursos al interior de las familias. El interés por el lugar de los recursos económicos en las relaciones de género se vincula con la capacidad reproductora

\footnotetext{
Instituto de Estudios Internacionales INTE, Universidad Arturo Prat, Iquique-Chile. marcela.tapia@ unap.cl Centro de Investigaciones Socioculturales, CISOC, Universidad Alberto Hurtado, Santiago, Chile.

Grupo OTRAS. Perspectivas Feministas en Investigación Social. Universidad de Granada, España. hgonzalv@uahurtado.cl
} 
del orden de género contenido en la migración y por la posibilidad de favorecer procesos de autonomía, especialmente de las mujeres que migran. De ahí que indagar por el impacto que tienen las remesas en las relaciones de género es central para comprender el potencial transformador que tiene el envío de remesas, tanto por la responsabilidad de la provisión económica que asume el/la migrante como por la administración de los recursos de los beneficiario/as, y por la independencia que puede representar la producción de recursos económicos para las mujeres.

La metodología aplicada en la investigación realizada se trazó en estrecha relación con la perspectiva epistemológica adoptada que reconoce dos premisas fundamentales: por un lado, el género es una construcción social, y por otro lado, la capacidad de agencia de las personas que les permite transformar la realidad existente (Acker 1990). En este sentido, la incorporación del género en el análisis de la movilidad internacional supone su reconocimiento en la toma de decisiones, en las trayectorias migratorias y en las vivencias de migrantes, no migrantes y receptores de remesas. Asimismo, el desplazamiento más allá de las fronteras alberga la posibilidad de transformación en las identidades y representaciones de género como lo han demostrado algunas investigaciones (Ariza 2000; Camacho y Hernández 2005; Hirsch 1999; Poggio 2000).

El método utilizado fue eminentemente cualitativo a través de entrevistas semiestructuradas a familias colombianas que contaban con un miembro (padre o madre) en Madrid. Las entrevistas fueron realizadas siguiendo la propuesta teórica de Marcus (1995) respecto de la necesidad de multisituar los estudios de caso y relativizar las fronteras nacionales en el análisis de los fenómenos globales. Si bien en distintos países de América Latina se han realizado trabajos empíricos sobre migración, la mayoría de las investigaciones se han situado o en el país emisor o en el país receptor. A diferencia de lo señalado, en la investigación presentada se aplicó una metodología que integró ambos espacios en el trabajo de campo al entrevistar a las unidades familiares transnacionales cuyos miembros se ubicaban entre Madrid y AMVA y AMCO. De este modo se aplicó la entrevista a nueve familias formadas por tres y cuatro miembros -padres, madres, hijos y cuidadores-, aplicadas durante los meses de marzo a septiembre del año 2008 .
En concreto, la muestra se caracterizó por tratarse de unidades familiares de los estratos socioeconómicos 2-3 y $4^{4}$, con experiencia migratoria en España (de uno o varios de sus miembros) con un tiempo mínimo de un año, con una frecuencia de remesas económicas de por lo menos 10 remesas en 12 meses, y con hijos/as de hasta 18 años y en situación de dependencia económica. Se realizaron 28 entrevistas a un total de 9 familias instaladas entre la Comunidad de Madrid, España, y AMCO y AMVA en Colombia. Una vez analizadas las entrevistas se procedió a tipificarlas teniendo en cuenta la historia migratoria y los cambios sufridos durante el proceso. Por tanto, lo que encontramos fueron preferentemente familias monoparentales ${ }^{5}$ con jefatura femenina; en número menor las familias extensas ${ }^{6}$; y finalmente las familias nucleares ${ }^{7}$ que se rompieron en el transcurso convirtiéndose en familias monoparentales con jefatura femenina.

Para el análisis de las entrevistas enfatizamos la mención de sus miembros en relación a la tipología de familias encontradas en la muestra. Esta opción tuvo por objetivo relevar la realidad interactiva y dinámica del grupo familiar desde la cual indagamos las motivaciones, expectativas y objetivos de los individuos de la unidad familiar que participaron en esta investigación ${ }^{8}$.

\section{Género, Familias y Remesas en los Estudios sobre Migración}

En la década de los ochenta del siglo pasado se incorporó la perspectiva de género a los estudios de las migraciones internacionales en las Ciencias Sociales (Morokvasic 1984; Phizacklea 1983), momento desde el cual se experimentó un incremento de las investigaciones relativas al género y la movilidad humana (Gregorio 1998). Son numerosas las publicaciones, especialmente en el ámbito anglosajón, que han señalado un camino metodológico y teórico que nutren las actuales investigaciones y señalan nuevos derroteros para la indagación del tema (Brettell y deBerjois 1992; Hondagneu-Sotelo 1999). España se incorporó en los años noventa a la investigación que vincula género y migración, y fue entonces cuando las remesas económicas se convirtieron en una de las principales categorías de análisis. Desde ese momento se han llevado a cabo numerosos estudios en torno a la temática migratoria en el afán de dilucidar el impacto de la migración en la sociedad receptora, emisora y en 
el espacio transnacional (Aurabell 2000; Bardají 2006). Sin embargo, es necesario avanzar en las investigaciones que se preocupan por el impacto de las remesas en las relaciones de género en un contexto familiar transnacional como es el caso de este trabajo.

Respecto al interés por analizar la vinculación entre género y migración, se advierte que una de las disciplinas que más se han ocupado de esta relación ha sido la Antropología. La mayoría de las investigaciones realizadas desde este ámbito se han orientado en dos direcciones según Gregorio (2008), por un lado, aquellas que se centran en el campo de la reproducción social, y por otro, aquellas que tienen como foco de interés el cambio social. Las primeras ponen de relieve la migración femenina en el marco de la crisis global de los cuidados y la visibilización del trabajo reproductivo no pagado de mujeres autóctonas. En tal escenario se produce la inscripción de las mujeres migrantes en el mercado laboral español bajo condiciones de discriminación étnica y de género (Oso 1998; Parella 2003). Las segundas se abocan al análisis de la reproducción $\mathrm{y}$ transformaciones en las relaciones y sistemas de género de las mujeres migrantes y en cómo la migración es tanto una oportunidad para la continuidad como para el cambio (Gregorio 2008; Tapia 2011a). En general, estos estudios han indagado por el impacto que produce la interacción de dos sistemas de género -el sistema de origen y el sistema de destino-, el mercado de trabajo en el país de recepción y el marco jurídico sobre extranjería en hombres y mujeres migrantes (Colectivo IOÉ 1998; Gregorio 1998; Parella 2003). En estos trabajos se han privilegiado elementos del sistema de estratificación sexual del trabajo y las relaciones de poder, así como el escenario que permite tomar decisiones sobre la propia vida y sobre la vida de los demás. Aspectos como la decisión del gasto de los recursos económicos, la elección de la pareja, la sexualidad y las derivadas del propio proceso migratorio han sido algunos de los elementos revisados (Gregorio 2008).

Con relación a las remesas y la migración internacional en América Latina existe una preocupación por conocer la magnitud del impacto que estos recursos han tenido en el crecimiento económico de la región, en la superación de la pobreza y en el desarrollo de los países receptores (CEPAL/ CELADE 2006; Mejía 2004; Moré 2005). Para el año 2007 se estimó que las remesas recepcionadas por el continente alcanzaron un poco más de US\$ 60.000 millones experimentando un crecimiento continuo y constituyéndose en una de las entradas más importantes del gasto corriente de los países latinoamericanos (Banco Mundial 2010). Entre los principales destinatarios de las remesas para el mismo año, Colombia se ubicó en segundo lugar detrás de México (US\$25.000 millones) con US\$ 4.600 millones (Banco Mundial 2010). Estos recursos han permitido a las familias de los emigrantes aliviar las condiciones de pobreza, concretar aspiraciones de mayor bienestar y oportunidades e incluso propender al desarrollo de las localidades de origen en algunos casos (CEPAL 2006; Martínez 2003)

En general, la mayoría de los estudios coinciden en señalar que las remesas aportan al gasto corriente de las familias de los migrantes, permiten aumentar la inversión en capital humano, facilitan el acceso a bienes de larga duración como la vivienda y ayudan a mejorar la calidad de vida de las familias receptoras (Solimano y Allendes 2008). También se ha señalado el impacto negativo que tienen las remesas especialmente en términos que pueden incentivar más migración, la tendencia a aumentar la inflación en el país receptor o que el uso de esos recursos no siempre se destina a inversiones productivas, sino más bien a gasto superfluo (CEPAL/CELADE 2006). En particular, para el caso de las mujeres remitentes se evidencia una mayor regularidad en los envíos, un mayor porcentaje de envío sobre los ingresos totales femeninos y un mayor beneficio en hogares con más miembros que responden a las necesidades básicas de las familias como nutrición, educación y salud (Garay y Rodríguez 2005b; ONU 2006).

Al revisar las investigaciones que vinculan género y remesas, se advierte un menor desarrollo de aquellos trabajos que indagan por el impacto de las remesas en las relaciones de género al interior de las familias. Esta situación es particularmente llamativa cuando se constata la persistencia de un patrón migratorio feminizado, como es el caso de latinoamericanas a Europa durante el boom migratorio. Este hecho se asocia en los países emisores con el aumento de la jefatura femenina de los hogares y la mayor participación de las mujeres en el mercado laboral formal e informal en los contextos de origen (Arriagada 2007). En los países receptores se relaciona con el envejecimiento de las sociedades desarrolladas, la permanencia de las nacionales en el mercado laboral, y el aumento de la demanda de los trabajos de cuidados (servicio 
doméstico, cuidado de personas dependientes, etc.) en los contextos de destino (Comisión Europea 2004; Parella 2003).

En este escenario se verifica que las motivaciones para migrar son coincidentes entre mujeres y hombres migrantes, es decir, fundamentalmente con fines laborales para luego enviar remesas al país de origen y dar un mayor bienestar a quienes se quedan (Curran y Saguy 2001; Pedone 2006; Tapia 2010). El aumento de la proporción de mujeres en los flujos migratorios llama la atención porque es frecuente que las mujeres migrantes asuman el rol de provisión económica de sus familias y por el impacto de las remesas en las relaciones de género. Estos cambios tienen sus antecedentes en las crisis económicas del continente, lo que ha promovido la flexibilidad laboral, una mayor cesantía para los hombres y el crecimiento de la economía sumergida (CEPAL/ CELADE 2006). Asimismo, se registran cambios en la familia que han dado lugar a un aumento de las familias monoparentales femeninas, fenómeno que explica la asunción activa de la provisión económica familiar por parte de las mujeres (Arriagada 2002).

Los estudios que vinculan género y remesas señalan que una vez que se concreta la migración y se produce el acceso al mercado de trabajo laboral en la sociedad receptora se produce, en algunos casos, una mejora en la correlación de fuerzas de carácter patriarcal y alteraciones en las relaciones de poder al interior de las familias y de la pareja (Kribia 1990). Aunque no es un proceso unidireccional, las investigaciones que incluyen el género en la administración de los recursos económicos señalan que la gestión femenina del dinero no se convierte necesariamente en más poder para las mujeres (Gregorio 1997) y que existen otros factores que pueden tener mayor peso; sin embargo, no se desestima su importancia (Dema 2006, Vogler y Pahl 1999). Aspectos como el tipo de relación de pareja y la historia familiar previa a la migración son algunos elementos que pueden marcar las diferencias.

En este panorama queda todavía por indagar cuál es el impacto de las remesas en las relaciones y prácticas de género en las familias vinculadas a la migración (Giménez 2003; Gonzálvez 2010) o familias transnacionales (Bryceson y Vuorela 2002), en las identidades y representaciones de género de quienes migran y en sus entornos familiares y sociales. Para mayor precisión de los conceptos utilizados en este trabajo y sin pretender abundar en la producción teórica sobre género, se entiende por relaciones de género aquellos vínculos que se construyen a partir de la diferencia sexual y las definiciones sociales, culturales e históricas que se derivan de lo femenino y lo masculino. Esas relaciones se traducen en prácticas de género, es decir, en comportamientos, actitudes y expectativas que hombres y mujeres realizan a partir de las normas y representaciones de género (Boyd 2006). Un elemento central en estas interacciones es el poder que se encuentra desigual y asimétricamente repartido en desmedro de las mujeres, lo que produce relaciones de dependencia, sumisión o subordinación (Acker 1990; De Barbieri 1992).

Por lo tanto, para el análisis social, el género no es una adición, sino una parte integral de las relaciones sociales que se expresa en la división del trabajo, en la construcción de símbolos e imágenes, en las interacciones entre mujeres y hombres y en los componentes individuales de la identidad (Acker 1990). En este sentido es pertinente utilizar el concepto de sistemas de género o estructura de género, que remite a la totalidad de la organización social y a los aspectos simbólicos, culturales y políticos, contenidos en esas relaciones (De Barbieri 1992; Saltzman 1989). Ello permite articular el sistema de género con otros sistemas de desigualdad, como el de clase, etnia o nacionalidad y dar una comprensión más amplia del vínculo entre género y migración.

En lo que respecta a este trabajo adherimos a la afirmación acuñada por Boyd y Grieco (2003) que señala que el género es el principio organizador de las migraciones en tanto las definiciones de lo masculino y lo femenino afectan al proceso y al resultado de la movilidad humana. De modo que el análisis de las relaciones y prácticas de género en contextos migratorios adquiere un lugar central en el estudio de las familias transnacionales, puesto que las condiciones en las que se toma la decisión de partir y los patrones migratorios influyen en dichas relaciones y éstas son afectadas por las representaciones y prácticas de género.

De este modo, la relación entre migración y género ocurre de forma conectada, en el entendido que la migración influye en las relaciones y prácticas de género que se dan en las unidades familiares, ya sea afianzando las desigualdades o bien desafiándolas. Las investigaciones advierten que el patrón femenino de la migración implica el intercambio de responsabilidades de género de manera temporal o permanente por parte de los hombres que se quedan (Pingol 2001; Poggio 2000). El patrón masculino 
de la migración altera menos el reparto de tareas y responsabilidades de género, pero en algunos casos se aprecia una sobrecarga para las mujeres no-migrantes (Hondagneu-Sotelo 1992) y en otros se traduce en la reafirmación del mandato de proveedor en los varones o nuevos aprendizajes para los varones (Osella y Osella 2000). Segundo, el género influye en las expectativas y en las motivaciones que tienen hombres y mujeres para migrar, aunque las expectativas económicas pueden ser coincidentes, las motivaciones se ajustan más a los mandatos y representaciones de género (Tapia 2011b). Y tercero, la variabilidad de género impacta en las familias de lo/as migrantes y en los procesos de fragmentación y reconfiguración familiar una vez que ocurre la migración, desencadenando transformaciones o permanencias en los significados de género y parentesco para cada uno de sus miembros a ambos lados del Atlántico (Gonzálvez 2009, 2010; Rivas y Gonzálvez 2011).

\section{El Enfoque Transnacional para la Comprensión de la Relación entre Remesas y Familias Migrantes}

En la actualidad las investigaciones sobre movilidad humana y género han sumado los aportes del paradigma transnacional que define la migración como un proceso fluido y relacional que no supone necesariamente ruptura con el país de origen. El carácter interdisciplinar que caracteriza a los estudios transnacionales ha visibilizado la contribución teórica que implica analizar el género como construcción social y activo organizador de las migraciones (Morawska 2003; Pessar y Mahler 2003). Dentro del amplio corpus investigativo sobre familia, migración y género, los estudios más frecuentes se refieren al análisis de género en familias transnacionales (Mahler y Pessar 2006:44); mientras que la relación entre remesas, familia y género en contextos transnacionales es aún un ámbito menos explorado.

En concreto, y siguiendo los diagnósticos y estudios sobre familia a nivel mundial y latinoamericano, sabemos que lo que existe en la realidad es una multiplicidad de formas de familia y de convivencia (García y Rojas 2004; Jelin 2006; Puyana 2004). Esta variedad de situaciones se relaciona con procesos de democratización de la vida cotidiana actual y la extensión de derechos de las personas, especialmente de las mujeres. Existe acuerdo respecto de la interrelación de fenómenos culturales, económicos y demográficos que han supuesto transformaciones en las familias en el contexto de procesos de modernización de las sociedades latinoamericanas en un mundo globalizado. En este escenario, uno de los aspectos más notorios de los cambios sociales, especialmente en las últimas décadas, se relaciona con la transformación del papel de las mujeres al interior de las familias, la disminución del número de hijos y el aumento de las familias monoparentales femeninas, entre los aspectos centrales. En esa conjunción de cambios uno de los aspectos notables se relaciona con el ingreso de las mujeres en el mercado de trabajo y la tendencia a permanecer en él, ya no sólo en tiempos de crisis como había ocurrido en el pasado, sino más allá de los hijos y del matrimonio (Ariza y Oliveira 2001; Chant y Craske 2003).

En este contexto de transformación de la familia, la migración internacional se ha constituido cada vez más en una alternativa para quienes no ven satisfechas sus expectativas económicas o de mejora del bienestar familiar y personal en el país de origen. Gracias a los abaratamientos del coste de las comunicaciones, el acceso a redes migratorias y las recurrentes crisis económicas y políticas en Latinoamérica se ha creado, en varios casos, un escenario propicio para que las mujeres y los hombres ya no vean la vida como destino (Appadurai 2001) y se planteen la migración como una estrategia familiar de aumento de ingresos. Todo ello en un contexto en que la corresidencia ya no es un criterio de pertenencia a los hogares (Ariza y Oliveira 2001), por lo menos temporalmente.

Así las remesas constituyen el aspecto más visible de la transnacionalidad en tanto mantienen unidas a las familias vinculadas a la migración e implican una inyección de dinero que les permiten alcanzar un mayor bienestar. Las remesas, a diferencia de otros recursos, son constantes y van directo a los bolsillos de los beneficiarios sin pasar por burocracias estatales y pueden suponer la diferencia entre la indigencia y la pobreza (Arroyo 2009; CEPAL 2006). Asimismo estos recursos permiten alcanzar una mejor calidad de vida de esas familias debido a la posibilidad de iniciar pequeños emprendimientos, acceder a la casa propia, mejorar el acceso a la educación de los hijos e incluso repercutir en las comunidades de origen a través de proyectos de desarrollo (De la Torre y Alfaro 2007). En resumen, el impacto de carácter transnacional sobre 
las relaciones familiares y de género producto de la provisión, envío y administración de las remesas es imposible obviar en los estudios sobre migración.

\section{La familia antes de la migración: Entre el cuidado y la provisión económica en un contexto transnacional}

Como punto de partida del análisis nos remitimos a los rasgos predominantes de las familias estudiadas en la etapa previa a la migración. Dicho periodo se constituye en el referente para analizar de qué manera impactan las remesas en las relaciones de género. El propósito de relevar la fase de partida como hito que marca un antes y un después tiene relación con el afán de conocer el impacto de la movilidad internacional y la consecución de remesas en las familias vinculadas a la migración a partir de la voz de las propias entrevistadas (Menjívar 1999; Zentgraf 2002).

Respecto de las unidades familiares analizadas y las relaciones de género predominantes en ellas se advierte la preponderancia de relaciones inequitativas y significativamente desiguales, lo que se convirtió en una dificultad para tomar la decisión de migrar en las mujeres. La situación de las familias en Colombia en las últimas décadas ha estado marcada por las transformaciones en las formas tradicionales de división de roles y funciones de acuerdo al sexo. En el pasado, las mujeres estuvieron mayormente supeditadas a la vida doméstica; sin embargo, cada vez más ocupan espacios que antes eran eminentemente masculinos, como la educación superior y el mercado laboral (Puyana 2004). Con todo, las familias analizadas se encuentran inmersas principalmente en un sistema de género desigual, pese a los cambios recientes que actualmente procuran mayor inclusión para las mujeres (Dammert y Bailey 2005).

En el caso de las familias monoparentales con jefatura femenina, la mayoría de las mujeres cumplían con una doble función, puesto que desempeñaban las labores correspondientes a la reproducción, tales como el cuidado de los hijos y el mantenimiento de la vida y al mismo tiempo eran proveedoras o coproveedoras económicas de sus familias. Entre las estrategias conciliadoras se puede mencionar la realización de trabajo productivo al interior del hogar, como la instalación de pequeños negocios o venta de comida. Asimismo, el recurso de acudir a otras mujeres, generalmente hermanas o madres, para la realización de las labores de cuidado o las funciones reproductivas, mientras ellas trabajaban. Con frecuencia este tipo de prácticas no supuso una ruptura entre el hogar y el trabajo, puesto que las actividades que se realizaban para obtener recursos económicos pertenecían al ámbito de la labor, es decir, actividades para el mantenimiento de la vida como cuidado y alimentación (Arendt 2005). Sin embargo, ninguna de las estrategias utilizadas permitió a estas mujeres insertarse en relaciones de equidad e igualdad de género o producir rupturas importantes en las relaciones y prácticas de género en las que socializaron a sus hijos e hijas.

En el caso de las mujeres jefas de hogar separadas antes de migrar, se aprecia que éstas asumieron un doble papel después del divorcio. La separación significó mayor dificultad al perder el apoyo económico y personal de sus parejas. Sin embargo, en los casos en que la relación de pareja estaba vigente, la presencia de los cónyuges no implicó un mayor aporte económico o un reparto equitativo en las tareas del hogar, tampoco equidad en las relaciones y prácticas de género en la familia. Por el contrario existían carencias en cuanto al cumplimiento de las responsabilidades tradicionales de género de los hombres, lo que no implicó la pérdida del poder masculino, como lo señaló una de las entrevistadas;

No, mi mamá siempre ha visto por nosotros, mi papá vive muy lejos, mi papá nunca, nunca... Pues nunca ha sido buen padre, nunca ha visto por nosotros, siempre, ha sido mi mamá (Hija, 22 años, Medellín).

En esos casos, la familia extensa fue un recurso que facilitó la crianza y cuidado de los hijos de las madres migrantes (Puyana 2004). De modo que la alternativa de volver al hogar extenso, luego del divorcio, les permitió hacer frente a la crisis de empleo y conjugar el cuidado con el trabajo fuera del hogar. Este expediente ha sido un recurso histórico al que se han acogido los miembros de la familia afectada por la crisis económica o familiar en Colombia (Gutiérrez de Pineda 2001) y en el resto de América Latina (Puyana 2004).

En estas familias, los varones entrevistados realizaban básicamente dos tipos de actividades remuneradas: trabajos independientes como ventas por cuenta propia, prestación de servicios, entre otros; y trabajos dependientes como obreros en empresas y cargos públicos, etc. Si bien, los empleos de los 
hombres también eran precarios e inestables -como los de las mujeres-, la diferencia en términos de prácticas y relaciones de género es que ellos estaban circunscritos de forma exclusiva al ámbito de la producción, sin ocuparse de las tareas de reproducción adscritas al ámbito doméstico. En la socialización de los hijos tampoco se encontraron pautas diferentes encaminadas a modificar las relaciones de género imperantes en la familia.

En general se encuentra que en la etapa anterior a la partida las relaciones y prácticas de género predominantes se encuadraban en una relación de división de tareas por sexo en el marco de una estructura de género jerarquizada. Aunque las mujeres desarrollaban actividades productivas y en varios casos eran las proveedoras de hecho de sus familias esto no supuso el abandono del trabajo doméstico ni de las labores de cuidado. En el caso de los varones que en la mayoría de las veces realizaban trabajos remunerados en condiciones precarias, su condición no implicó la asunción de tareas en el ámbito doméstico o una mayor participación en el cuidado de los hijos.

\section{Las remesas como incentivo para la migración} internacional de colombiano/as a Madrid

Las mujeres como los hombres pertenecientes a las unidades familiares analizadas que decidieron migrar, manifestaron que la falta de empleo y la ausencia de oportunidades para mejorar las condiciones de vida de sus hijos y sus familias los llevó a pensar en la migración internacional. En este sentido, tanto en las mujeres como en los hombres la motivación laboral y la obtención de recursos económicos en el país de destino fue un elemento central en la configuración de la empresa migratoria. La falta de empleo o la existencia de trabajos precarios, cuyo salario era insuficiente para la manutención de la familia -aunque la mujer también generase recursos-, alentaron a los padres de las familias nucleares para dar continuidad al rol de proveedor familiar. En este escenario, España precrisis se configuró en un lugar propicio donde encontrar rápidamente trabajo, mejorar condiciones salariales respecto de las de Colombia y, por tanto, la posibilidad de enviar remesas a las familias que se quedaban.

Los estudios que abordan el periodo de estudio, como los basados en la Encuesta Nacional 2008-2009 sobre remesas, señalaban que en el caso de Bogotá el monto medio mensual de un hogar receptor de remesas ascendía a 272.356 pesos colombianos (107 euros o 140 dólares aproximadamente) (Mejía, et al., 2009). Para el año 2009 el salario mínimo en Colombia era de 496.900 pesos colombianos ${ }^{10}$; por tanto, la posibilidad de migrar para enviar remesas implicaba un aumento de los ingresos familiares. Así la migración a España se configuró en una estrategia para hacer frente a las dificultades existentes en el país de origen, facilitado además por las redes migratorias familiares o de amigos que alentaron la toma de la decisión.

Pues no sé, me dio por venirme a buscar un futuro mejor para mi familia, para mí, porque allá en Pereira estaba muy dura la cosa; lo que ganaba no me alcanzaba para los gastos, por eso decidí venirme por acá y aquí también hay familias, hay cuñados y todo, entonces me animé; fue por eso porque estaba el cuñado por acá (Padre, 50 años, Madrid).

No obstante la motivación laboral y el compromiso de enviar remesas fue un elemento común en los proyectos migratorios revisados, se apreciaron diferencias de acuerdo al tipo de familia y a las prácticas de género. En el caso de las familias monoparentales con jefatura femenina aparecieron elementos extraeconómicos como desencadenantes de la decisión de partir, como por ejemplo la ruptura matrimonial previa a la migración y, en otros casos, esa situación se desencadenó durante la migración. Sin embargo, fueron las consecuencias económicas de la ruptura lo que afectó a estas familias, entre ellas la pérdida de recursos, una menor participación e incluso ausencia de apoyo económico de la ex pareja o esposo y, en consecuencia, la imposibilidad de mantener a los hijos en solitario.

Perdí el trabajo y ya no conseguí trabajo. Empecé a hacerles limpiezas a mis amigas y me pagaban para que les limpiara la casa para comprarle la leche a mi niña y los pañales, porque me había dejado el papá de la niña y los niños estaban con el papá; los varones estaban con el papá de ellos, porque me los quitó. Prácticamente porque al niño lo amenazó que si no iba a vivir con él no les daba estudio ni les daba nada. Y el niño mayor mío me dijo 'mamá, lo siento 
mucho, pero quiero estudiar' (Madre, 25 años, Madrid).

En la mayoría de estos casos la migración de las mujeres jefas de hogar fue posible en la medida en que se concibió como una estrategia para mantener a la familia en un contexto transnacional. La posibilidad de contar con otras mujeres de la familia extensa para asumir las funciones de mantenimiento y cuidado familiar en Colombia facilitó la decisión de migrar. Casi siempre fueron abuelas, tías o cuñadas, y en algunos casos amigas, quienes colaboraron en la reconfiguración familiar, donde las mujeres alcanzaron un lugar fundamental en las denominadas cadenas de cuidado global (Ehrenreich y Hochschild 2004; Hochschild 2000).

Una vez concretada la migración se observó que la partida del padre o la madre migrante no se tradujo en transformaciones en la división sexual del trabajo de las unidades familiares estudiadas. En la mayoría de los casos fueron las mujeres las que se mantuvieron en los procesos de socialización, en el sostenimiento de la unidad familiar y en la administración de las remesas. En algunos casos se trató de mujeres sin hijos o que teniendo hijos propios, sumaron a los suyos los hijos ajenos (cuñadas, hermanas, amigas) y en otros casos fueron mujeres que habían terminado la crianza de sus propio hijos (abuelas). Así lo señaló una de las entrevistadas "mis hijos han sido los hijos de ella, siempre, desde que yo me separé, ella ha estado conmigo, ella ha sido casi mi ángel guardián" (Madre, 40 años, Madrid).

En general, tanto en los arreglos familiares como en la reorganización de las familias migrantes, la responsabilidad recayó tanto sobre las mujeres que partieron como en las que se quedaron. Fueron ellas las que construyeron los ajustes, de acuerdo al soporte que otorgó la familia extensa o la búsqueda de cuidadoras, que en todas las familias analizadas fueron mujeres con vínculos de consanguinidad o afinidad. De la misma manera ocurrió con las remesas, ya que en todos los casos revisados fueron las mujeres quienes asumieron la responsabilidad de administrarlas. Esta situación se ajusta a lo señalado por otras investigaciones que advierten del protagonismo de las mujeres como receptoras de las remesas y como remitentes ${ }^{11}$.

En el caso de las familias monoparentales de jefatura femenina la regularidad de los envíos fue mayor, y en gran parte de los casos el dinero se destinó para cubrir el funcionamiento de la familia en general. En este tipo de unidad familiar la administración de las remesas fue asumida por la cuidadora en asociación con los hijos/as, por lo general, la hija mayor. Las mujeres remitentes conservaron con ellas (cuñada, abuela o hermana) fuertes vínculos afectivos y de compromiso, fueron ellas quienes cuidaron a los hijos que se quedaron y procuraron que las remesas se gastasen de acuerdo con lo estipulado por la madre migrante. En general, entre las mujeres remitentes y las cuidadoras se mantuvo una relación de reciprocidad que se afianzó por los sacrificios mutuos que unas y otras realizan en los distintos espacios geográficos. De hecho, las cuidadoras asumieron también el cuidado a distancia de la madre migrante, tanto en el afán de mantenerlas al tanto de la situación familiar, como en evitarles disgustos o preocupaciones.

En relación a la configuración del gasto de las remesas, estudios previos han señalado que casi siempre éste ha quedado en manos de los jefes o jefas de hogar (Mejía, et al. 2009). Sin embargo, en nuestra investigación se aprecia que en las familias en las que había hijos adolescentes o jóvenes, ellos también participaron en la decisión del gasto de las remesas. Los hijos de estas familias, especialmente adolescentes, adquirieron mayor protagonismo, pero al mismo tiempo mayor responsabilidad por la necesidad de responder a lo que entendieron era un sacrificio de sus madres.

Primero nosotros cogemos y hacemos una lista de todo lo que necesitamos: colegio... todo, todo lo que nos haga falta... que crema de manos... pues cosas así, cosas así sin importancia, pero igual hacen falta y entonces ella ya dice (la madre migrante); para Sandra esto y para Alejandro esto que le hace falta y ya mi tía la recibe y nos dice: vea Alejandro, lo que le mandó la mamá para que gaste, para esto.., pues sí, para todo, entonces lo reparte entonces así (Hija, 22 años, Medellín).

Es relevante señalar para esta forma familiar, que los esfuerzos que hicieron las mujeres para mantener los envíos estuvieron menos condicionadas por las coyunturas existentes en el país de destino. Las mujeres migrantes remitentes desplegaron estrategias como el pluriempleo, préstamos, créditos para mantener la regularidad de los envíos. 
Respecto al uso de las remesas por parte de las familias receptoras, se observó que para el caso de las familias extensas con unidad monoparental la frecuencia fue más irregular y su uso quedó asociado a las necesidades puntuales y situaciones de emergencia. Por lo tanto, la recepción de remesas implicó la existencia de un ingreso adicional, ya que por lo general otros miembros de la familia que no migraron continuaban aportando al sostenimiento familiar. En estas unidades familiares fue frecuente que quien administraba las remesas fuesen las cuidadoras de los hijos, en su mayoría, abuelas maternas.

Para el caso de las familias nucleares existen diferencias con respecto a quien migró, el padre o la madre. De esta forma, cuando la migración la realizó el padre las remesas contribuyeron a reafirmar el rol de padre-proveedor al interior de la familia. En este caso los recursos enviados fueron el principal ingreso de la familia en origen, y fueron interpretados por todos los miembros de la unidad familiar como una forma de mantener los vínculos afectivos y de dependencia. La esposa o pareja en Colombia actuó como administradora de las remesas y a su vez realizó el trabajo de cuidado y las tareas domésticas, trabajos que ya desempeñaba antes de la migración de su cónyuge. En este caso las relaciones de género se mantuvieron inalteradas. Por el contrario, cuando la migración la realizó la madre las remesas sirvieron para mantener ocasionalmente a los miembros de la familia, y el padre en origen siguió manteniendo su rol de proveedor principal. En estos casos los envíos de las mujeres fueron más esporádicos y se destinaron a gastos ocasionales.

Como hemos argumentado, las madres y los padres migrantes colombianos tenían como objetivo encontrar trabajo para obtener un salario suficiente, tanto para su manutención en el país de recepción, como para enviar dinero a sus familias en el país de origen. En la mayoría de los casos las remesas tuvieron como destino el pago de deudas, gasto en alimento y servicios, compra o mejora de la vivienda, y en general mayor bienestar para los hijos y familiares que quedaron en Colombia. Esta situación es consistente con lo que han señalado las investigaciones sobre remesas que advierten del uso de las mismas en ítems como alimentación, educación, salud, vivienda y, en menor medida, ahorro (Garay y Rodríguez 2005a, 2005b).

En general se aprecia que el envío de remesas supuso una reconfiguración de la organización familiar y nuevas formas de interacción al interior de las familias colombianas estudiadas. Las relaciones de género entre migrantes y no migrantes también fueron influidas; en tanto se observó un cambio en las relaciones entre el emisor y el receptor/administrador de las remesas pasando de una relación más recíproca a una de mayor jerarquía. Una vez que se concretó la migración y se materializó el envío de remesas aparecieron tareas y obligaciones distintas para migrantes y no migrantes, y se establecieron relaciones de poder diferentes influidas por los recursos económicos. Este cambio en la relación implicó tensiones y conflictos en algunos casos, y la asunción de nuevas responsabilidades, pero no afectó la división de tareas de acuerdo al sexo, ni las relaciones de jerarquía entre hombres y mujeres.

En general, lo que se advierte en términos de nuevos roles y tareas de migrantes y no migrantes a partir del envío de las remesas, es que en la mayoría de los casos las nuevas tareas se relacionaron con los acomodos que implicó la propia migración y la continuidad de la familia de acuerdo con las pautas de género establecidas por la sociedad. La necesidad de buscar nuevos arreglos en la vida familiar y mantener el rol a distancia de quien partió, hombre o mujer, hizo que los miembros de la familia asumieran una parte o la totalidad de las tareas de quien migró. En general se aprecia que el orden de género no se alteró por la circulación de remesas, la reorganización familiar se relacionó más con los roles y responsabilidades de género de los distintos miembros de las familias y en algunos casos se tradujo en más trabajo y mayores responsabilidades, especialmente si quien migró era mujer.

\section{Hacia una nueva valoración de las mujeres remitentes: recompensas y continuidades}

Una vez en España, las transformaciones más notorias se aprecian en las mujeres migrantes provenientes de familias monoparentales con jefatura femenina. La mayoría de estas mujeres se insertaron en el mercado laboral en oficios y trabajos feminizados, como limpieza, servicio doméstico, cuidado de personas y trabajo en oficinas. Las que llegaron antes del año 2002 ingresaron como turistas al país para permanecer como irregulares y luego beneficiarse de la regularización del $2005^{12}$. Esa situación les permitió acceder a trabajos estables y mejor remunerados, pero siempre dentro del 
segmento ocupacional menos valorado socialmente (Parella 2003; 2004).

En todos los casos, las mujeres enviaron remesas a sus familias para cumplir con el compromiso asumido antes de partir. El uso de estos recursos permitió responder a las responsabilidades familiares y con ello atenuar el sacrificio de dejar a sus hijos en Colombia. De esta forma, las mujeres percibieron una mayor valoración por los logros económicos y experimentaron un aumento en la autoestima, el cual se evidenció al momento de evaluar su experiencia migratoria en España.

Yo he trabajado mucho aquí, pero yo ahora dos años que me fui, me hice la tercera plantica, mi casa era de dos plantas y yo iba con la ilusión... me recogí un dinero, eran 27 millones... dos cosas que estando aquí he logrado es darle la universidad a mi hija, porque fueron cinco años que yo se los di de universidad y la casa... (Madre, 42 años, Madrid).

Asimismo, se aprecia una mayor valoración por parte de la familia no-migrante gracias al envío de remesas, lo que incidió en que los hijos y parientes le otorgasen un lugar destacado y un mayor reconocimiento. Los recursos económicos producidos por las mujeres, tanto al interior del hogar o como fuera de él antes de la migración no eran valorados por ellas ni por sus familias. En cambio cuando la mujer migrante envió remesas desde España se experimentó un cambio en la percepción de sus familiares hacia ellas, especialmente porque accedieron a mayores recursos comparados con los que ganaban en Colombia antes de la partida. Este hecho les permitió satisfacer las necesidades familiares con más facilidad y hacer frente a situaciones que requerían de mayor cantidad de dinero y, por tanto, provocaron una mejora sustantiva de sus condiciones de vida. En este escenario se reafirmó la idea de mujer como la madre incondicional y altruista dispuesta a hacer todo lo que sea necesario por sus hijos/as, de modo que la valoración se dio en un doble sentido, como madre y como proveedora.

Yo cuando vivía allí, yo iba a visitar a mi madre y cuando yo le tocaba la puerta decía: 'ya viene ésta a joder otra vez'. Y ahora cuando la llamo por teléfono: 'Hijita mía que Dios la bendiga’ (¿Y por qué crees que ha habido ese cambio?) por el dinero, porque ahora tengo dinero, tengo formas de ayudarles, forma de mandarle un dinero. Antes yo no tenía nada, nada. Nada que ofrecerle a nadie (Madre, 40 años, Madrid).

En todos los casos el envío de remesas por parte de las mujeres no significó empoderamiento para ellas, pero sí una valoración distinta de sí mismas respecto de la fase premigratoria. Si bien se produjo una reafirmación de los roles derivados de la maternidad, la mayoría de las mujeres consideradas en esta investigación experimentaron una mayor satisfacción de logro. Esta situación se relaciona especialmente con la experiencia migratoria, la superación de los obstáculos encontrados en Madrid y la posibilidad de concretar proyectos de mayor envergadura como la compra de una vivienda o el pago de la universidad de los hijos.

En cuanto al impacto que se aprecia más allá de las remesas, llama la atención las nuevas relaciones de pareja de algunas de las mujeres de la muestra. De las nueve unidades familiares analizadas, en cinco de ellas las mujeres migrantes establecieron nuevas relaciones de pareja en España con hombres no colombianos (europeos y latinoamericanos). Estas relaciones se asumieron como una nueva oportunidad en la vida de las madres migrantes, quienes valoraron el apoyo, la compañía y la solidaridad que reciben de sus nuevas parejas. También se apreció una búsqueda de identidades masculinas no hegemónicas, es decir, aquellas que se constituyen como masculinidades-tipo en el contexto de la sociedad colombiana (Viveros 2001). En este sentido, las mujeres migrantes manifestaron explícitamente su deseo de no volver a establecer relaciones con hombres de su país debido a las experiencias insatisfactorias que tuvieron con ellos antes de migrar. La posibilidad de establecer un nuevo tipo de relación con personas que reconocieran su trabajo y fuesen activos en la realización de las tareas domésticas fueron elementos centrales en la valoración de la nueva relación.

... nunca creí que fuera a conocer eso, nunca me imaginé que iba a tener alguien que me quisiera, respetara y valorara. Como pareja me siento realizada, porque en la intimidad muy bien, a mí me había ido muy mal. Como persona me valora, respeta y me tiene en cuenta, hasta para lo que vamos a 
cenar esta noche. Tiene detalles conmigo y con mis hijos (Madre, 40 años, Madrid).

Otro aspecto a relevar fue la sensación de libertad y acceso a nuevos espacios y personas que la migración conllevó para algunas mujeres. La movilidad internacional y el envío de remesas representaron una nueva oportunidad para las madres migrantes, y aunque coincidieron en afirmar el sacrificio que suponía estar lejos de su país y de su familia, también señalaron que el esfuerzo había merecido la pena. No sólo porque con su trabajo mejoró la calidad de vida de sus familiares, sino porque esta experiencia las condujo a procesos de transformación personal como sentirse distintas, más fuertes y más independientes. Para aquellas que antes de migrar trabajaban en sus casas en negocios propios, aisladas, la experiencia migratoria les permitió conocer gente diferente y realizar nuevos aprendizajes, lo que les abrió nuevos horizontes, tanto para las migrantes como para las familias en Colombia. Asimismo, las entrevistadas señalaron que lograron más independencia y mayor fortaleza para afrontar las situaciones difíciles, especialmente de carácter familiar. En este proceso el envío de remesas ha sido relevante porque permitió establecer una nueva relación de poder relacionada con el hecho de ser proveedoras, así como posibilidades de mando y autonomía en las decisiones importantes con respecto al hogar y la familia.

En cuanto a las permanencias, la mayoría de las personas entrevistadas se mantuvieron en oficios precarios o de mayor esfuerzo físico. Las mujeres se insertaron en trabajos feminizados como el trabajo doméstico, y/o cuidado de niños y ancianos. Trabajos que antes eran realizados en el ámbito doméstico y en algunas ocasiones en el ámbito productivo, y que después de la migración las realizaron en el ámbito de lo productivo y en un contexto transnacional. Es decir, la migración para las mujeres no representó mayores condiciones de equidad en lo laboral, ni la posibilidad de revertir las condiciones previas a la partida. De hecho reconocen que sus trabajos siguen siendo igual o más duros que los realizados en AMVA y en AMCO.

En todas las unidades familiares donde migraron mujeres, las relaciones y prácticas de género no fueron transformadas de manera sustantiva. En el caso de las familias monoparentales o nucleares donde migró la madre, ésta fue reemplazada por otra mujer que continuó haciendo las mismas tareas y reproduciendo las relaciones de subordinación femenina, la diferencia que se advierte es que la administración de las remesas aumentó la autonomía económica. Sin embargo, no se registran procesos de empoderamiento o emancipación femenina inducida por la acción de las remesas.

Respecto a la socialización de los niños en los distintos tipos de familias no se registró un proceso que promoviese las transformaciones en la división sexual del trabajo o una crianza que implicara cambios en las relaciones de género. Por el contrario, predominaron las permanencias tanto en la división sexual del trabajo como en las relaciones de género que se desarrollan en estas familias, contribuyendo de esta forma al mantenimiento del sistema de género en la que se encontraban inmersas.

\section{Conclusiones}

A partir de los hallazgos de la investigación realizada apreciamos que la circulación de remesas al interior de las familias transnacionales colombianas facilitó algunas transformaciones en las prácticas de género, pero no se vislumbran cambios significativos en las relaciones de género. Los principales cambios se relacionan más con la experiencia migratoria, especialmente en mujeres migrantes de familias monoparentales producto de la acción de las remesas. En este sentido, un aspecto central para dimensionar el impacto de las remesas económicas en las relaciones de género fueron las características familiares, sobre todo, la tipología familiar. En concreto, la variabilidad encontrada se relaciona con el patrón migratorio, es decir, si quienes migraron eran mujeres u hombres, y el tipo de familia de procedencia.

En la fase previa a la migración no se aprecian cambios en las prácticas ni en las relaciones de género en la medida en que los arreglos para migrar permitieron mantener y reproducir el orden de género. En algunos casos aumentó la carga en las mujeres que se quedaron en Colombia asumiendo las tareas de cuidado y reproducción de la vida familiar. Esto ocurrió con independencia del tipo de familia de las mujeres migrantes colombianas, no obstante, las familias no experimentan cambios sustantivos en términos de relaciones de género en esta etapa.

Se advierte que la motivación para migrar se constituye en una alternativa central para la sobrevivencia familiar, especialmente en las familias monoparentales de jefatura femenina con ruptura 
de pareja. Las escasas expectativas laborales en Colombia y la posibilidad de encontrar un trabajo mejor remunerado en España favorecido por las diferencias salariales alentaron la migración y el envío de remesas. Así la migración internacional se configuró en una estrategia que permitió concretar los objetivos familiares, facilitado por la acción de mujeres no-migrantes que se quedaron y que permitieron dar continuidad a la vida familiar. En este sentido se evidencia que los hombres o mujeres provenientes de familias nucleares o extensas contaron con mayores alternativas, porque cuando no prosperó el proyecto migratorio fue posible pensar en el retorno como último recurso.

Una vez concretada la migración en España, se mantuvo la diferenciación por género del impacto de las remesas en migrantes y no migrantes. Aunque no se aprecian cambios sustantivos en las relaciones de género inducidas por las remesas económicas, en algunos casos sí se observan nuevas recompensas, y es aquí donde el tipo de familia adquiere mayor protagonismo en la interpretación de estos cambios. Tales recompensas se relacionan con el impacto de la propia migración y por el acceso a los nuevos recursos económicos, especialmente entre las mujeres. Aunque la generalidad de las mujeres colombianas se inserta en oficios feminizados, las mayores posibilidades de inserción laboral permitieron persistir en los propósitos de la migración. En tales casos las recompensas tienen mayor impacto en las mujeres-madres provenientes de familias monoparentales por ruptura de pareja. La asunción de la provisión económica desde España, el envío de remesas y la certeza de que éstas se traducen en mayor bienestar familiar hizo que las mujeres migrantes ganasen en autoestima y valoración de sí mismas. En el caso de los varones, si la migración fue exitosa, ésta fue percibida como una extensión del rol de proveedor, si fracasaron el expediente fue el retorno para así intentar dar continuidad a ese mandato de género en Colombia.

De esta forma, en el estudio de las familias vinculadas a la migración la triada género, migración y remesas nos ha permitido observar que los aspectos que afectan las relaciones de género se relacionan más con el lugar de parentesco al interior de las familias que con el potencial transformador que por sí mismas pueden llegar a tener las remesas. Así se evidencia que la situación familiar afecta al proyecto migratorio, a las motivaciones para migrar e influye en la selectividad de quién migra dentro de la unidad doméstica. Por tanto, el lugar que les corresponde a las remesas como un potencial transformador de las relaciones de género está estrechamente vinculado a la posición de género y parentesco de quien decide partir. Asimismo, se observa que una vez producida la migración el impacto del envío y uso de remesas en las relaciones de género fue más notorio en las familias monoparentales con jefatura femenina. Con el tiempo algunas de estas familias establecieron nuevas relaciones de pareja, en definitiva, nuevas prácticas de género y parentesco que se tradujeron en que el impacto de la circulación de las remesas se relacionara con recompensas, entre ellas, un mayor bienestar de la familia no-migrante y una mayor valoración de las mujeres migrantes.

\section{Referencias Citadas}

Acker, J. 1990. Hierarchies, jobs, bodies: A theory of gendered organizations. Gender and Society 4 (2):139-158.

Alía, F. 2008. Técnicas de Investigación para Historiadores. Síntesis, Madrid.

Arendt, H. 2005. La Condición Humana. Paidós, Barcelona.

Ariza, M. 2000. Ya No Soy la que DejéAtrás... Mujeres Migrantes en República Dominicana. Instituto de Investigaciones Sociales/ Editorial Plaza y Valdés, México D.F.

Ariza, M. y O. Oliveira 2001. Familias en transición y marcos conceptuales en redefinición. Papeles de Población 28:9-39.

Arriagada, I. 2002. Cambios y desigualdad en las familias latinoamericanas. Revista de la CEPAL 77:143-161.

. _ _ 2007. Las familias y su vinculación con los mercados. En Género y cohesión social, editado por Judth Astellarra, pp. 15-25. Fundación Carolina 16, Madrid.
Arroyo, M. C. 2009. La Migración Internacional: Una Opción Frente a la Pobreza. Impacto Socioeconómico de las Remesas en el Área Metropolitana de La Paz. PIEB, La Paz.

Aurabell, G. 2000. Una propuesta de recorrido bibliográfico por las migraciones femeninas en España. Papers 60:391-413.

Banco Mundial 2010. América Latina y el Caribe. http:// siteresources.worldbank.org/INTPROSPECTS/Resources/3349341199807908806/4549025-1214334216239/LAC.pdf (17 de diciembre de 2010).

Bardají, F. 2006. Literatura sobre Inmigrantes en España. MTAS, Madrid.

Boyd, M. 2006. Women in International Migration: The Context of Exit and Entry for Empowerment and Explotation. United Nations, Toronto.

Boyd, M. y E. Grieco 2003. Women and Migration: Incorporating Gender into International Migration Theory Center for the Study of Population Working Paper 35:98-139. 
Brettell, C. y P. deBerjois 1992. Anthropology and the Study of Immigrant Women En Seeking Common Ground: Multidisciplinary Studies of Immigrant Women in the United States, editado por Donna Gabaccia, pp. 41-63. Greenwood Press, Connecticut.

Bryceson, D. y U. Vuorela 2002. The Transnational Family: New European Frontiers and Global Networks. Berg Publishers, Oxford.

Camacho, G. y K. Hernández 2005. Cambió mi Vida. Migración Femenina, Percepciones e Impactos. UNIFEM/CEPLAES, Quito.

CEPAL/CELADE 2006. Cuatro Temas Centrales en Torno a la Migración Internacional, Derechos Humanos y Desarrollo. CEPAL, Santiago de Chile.

Colectivo IOÉ 1998. Inmigración y Trabajo. Trabajadores Inmigrantes en el Sector de la Construcción. Imserso, Madrid.

Comisión Europea 2004. Hogares, Cuidados y Fronteras... Derechos de las Mujeres Inmigrantes y Conciliación. Traficantes de sueños, Madrid.

Consejería de Inmigración y de Cooperación de Madrid 2008. Informe de la población extranjera empadronada en la Comunidad de Madrid. http://www.madrid.org/cs/Satellite?blobcol=urldata \&blobheader=application $\% 2$ Fpdf\&blobkey=id\&blobtable $=\mathrm{Mu}$ ngoBlobs\&blobwhere $=1220355110798 \&$ ssbinary $=$ true $(29 \mathrm{de}$ noviembre 2012).

Curran, S. y A. Saguy 2001. Migration and Cultural Change: A Role for Gender and Social Networks? http://www.bridgew. edu/SoAS/JIWS/June01/Curran.pdf (1 junio 2009)

Chant, S. y N. Craske 2003. Gender in Latin America. Latin America Bureau, London.

Dammert, L. y J. Bailey 2005. Reforma policial y participación militar en el combate de la delincuencia. Análisis y desafíos para América Latina. Revista Fuerzas Armadas y Sociedad 19 (1):133-152.

DANE 2012. Estratificación socioeconómica. http://www.dane. gov.co/index.php?option=com_content $\&$ view $=$ article $\&$ id $=354$ \&Itemid=114 (30 de noviembre 2012).

De Barbieri, T. 1992. Sobre la categoría de género. Una construcción teórico-metodológica. En Fin de Siglo y Cambio civilizatorio, editado por J. Astelarra y R. Rodríguez, pp. ISIS, Ediciones de las Mujeres, Santiago de Chile.

De la Torre, L. y Y. Alfaro 2007. La Cheqanchada. Los Caminos y Sendas de Desarrollo en los Municipios Migrantes de Arbieto y Toco. Universidad Mayor de San Simón/PIEB, La Paz.

Dema, S. 2006. Una Pareja, dos Salarios. El Dinero y las Relaciones de Poder en las Parejas de Doble Ingreso. CIS, Madrid.

Ehrenreich, B. y A. R. Hochschild 2004. Global Woman: Nannies, Maid and Sex Workers in the New Economy. Henry Holt and Company, New York.

Garay, L. J. y A. Rodríguez 2005a. Características socioeconómicas de la población emigrante internacional ubicada en AMCO. En Memorias del Seminario: Migración Internacional, el Impacto y las Tendencias de las Remesas en Colombia, OIM, pp. 33-40. OIM, Bogotá.

Garay, L. J. y A. Rodríguez 2005b. Estudio sobre Migración Internacional y Remesas en Colombia. DANE, Bogotá.
García, B. y O. Rojas 2004. Las Uniones Conyugales en América Latina: Transformaciones en un Marco de Desigualdad Social y de Género. CEPAL, Santiago de Chile.

Giménez, C. 2003. Familias en la inmigración: su integración con la sociedad receptora. Familia e interculturalidad 129-196.

Gonzálvez, H. 2009. Vivir transnacionalmente. Colombianos y Colombianas entre Bello (Colombia) y Elche (España). En Lugares, Procesos y Migrantes. Aspectos de la Migración Colombiana, editado por A. González, pp. 253-278. PIE. Peter Lang, Bruselas.

- _ - 2010. Migración Colombiana, Género y Parentesco: la Organización Social de los Cuidados. Tesis para optar al grado de Doctor en Antropología y diversidad cultural, Departamento de Antropología y Trabajo Social, Universidad de Granada, Granada.

Gregorio, C. 1998. Migración Femenina. Su Impacto en las Relaciones de Género. Narcea, Madrid.

_. _ _ 2008. Análisis de las migraciones transnacionales en el contexto español, revisitando la categoría de género desde una perspectiva etnográfica y feminista. Nueva Antropología XXIV (74):39-71.

Gutiérrez de Pineda, V. 2001. Familia y Cultura en Colombia. Universidad de Antioquia, Medellín.

Hirsch, J. 1999. En el norte la mujer manda: Gender, generation and geography in a Mexican Transnational Community. American Behavioral Scientist 42 (9):1332-1349.

Hochschild, A. R. 2000. Las cadenas mundiales de afecto y asistencia y la plusvalía emocional. En En el límite. La Vida en el Capitalismo Global, editado por Hill Hutton y Anthony, pp. 187-208. Tusquets Editores, Barcelona.

Hondagneu-Sotelo, P. 1992. Overcoming Patriarchal Constraints: The Reconstruction of Gender Relations among Mexican Immigrant Women and Men. Gender and Society 6:393-415.

1999. Introduction. Gender and contemporary U.S Immigration. American Behavioral Scientist 42:565-576.

INE España 2012. http://www.ine.es/ (30 noviembre 2012)

Jelin, E. 2006. Pan y Afectos. La Transformación de las Familias. Fondo de Cultura Económica, México D. F.

Juliano, D. y D. Provansal 2008. Conocimiento, migraciones y género. En Retos Epistemológicos de las Migraciones Transnacionales, editado por E. Santamaría, pp. 339-373. Anthropos, Barcelona.

Kostova, M. 2006. Una Evaluación del Último Proceso de Regularización de Trabajadores Extranjeros en España (febreromayo 2005). Un Año Después. Real Instituto Elcano, Madrid.

Kribia, N. 1990. Power, patriarchy, and gender conflict in the vietnamese immigrant community. Gender and Society 4 (1):9-24.

Marcus, G. 1995. Ethnography in/of the world system. The emergence of mulsited Ehtnography. Annual Review of Anthropology 24:95-117.

Martínez, J. 2003. Panorama regional de las remesas durante los años noventa y sus impactos macrosociales en América Latina. Migraciones Internacionales 2:40-76.

Mejía, W. 2004. Estudio de migración y remesas internacionales en Colombia. http://www.migracionescolombianas.edu.co/ vieja/Documentos/documentos/DOCUMENTOS\%20DE\%20 TRABAJO/remesasw.pdf (29 de noviembre 2010). 
Mejía, W., D. Ortiz, C. Puerta, J. Mena y M. Díaz 2009. Encuesta Nacional 2008-2009. Resultados Generales de Migraciones Internacionales y Remesas. Observatorio distrital de migraciones/ Observatorio colombiano de migraciones, Bogotá.

Menjívar, C. 1999. The intersection of work and gender: Central American immigrant women and employment in California. American Behavioral Scientist 42 (4):601-627.

Morawska, E. 2003. Disciplinary Agendas and Analytic Strategies of Research on Immigrant Transnationalism: Challenges of Interdisciplinary Knowledge. International Migration Review 37:611-640.

Moré, I. 2005. Las remesas irrumpen en el modelo económico de Iberoamérica. En Anuario Elcano. América Latina 2004-05, editado por Carlos Malamud y Paul Isbell, pp. 211-235. Ariel/ Real Instituto Elcano, Madrid.

Morokvasic, M. 1984. Birds of passage are also women. International Migration Review 18 (4):886-907.

Nyberg Sorensen, N. y L. E. Guarnizo 2007. La vida de la familia transnacional a través del Atlántico: la experiencia de la población colombiana y dominicana migrante en Europa. Puntos de vista. Cuaderno del Observatorio de las Migraciones y de la Convivencia Intercultural de la Ciudad de Madrid 9:7-30.

Osella, F. y C. Osella 2000. Migration, Money and Masculinity in Kerala. The Journal of the Royal Anthropological Institute 6:117-133.

Oso, L. 1998. La migración hacia España de mujeres jefas de hogar. Ministerio de Trabajo y Asuntos Sociales/ Instituto de la Mujer, Madrid.

Parella, S. 2003. Mujer, Migrante y Trabajadora: la Triple Discriminación. Anthropos, Barcelona

- _ - 2004. Reclutamiento de trabajadoras inmigrantes en las empresas de servicios de proximidad en el Área Metropolitana de Barcelona. REIS 108:179-200.

Pedone, C. 2006. Tu Siempre Jalas a los Tuyos. Estrategias Migratorias y Poder. Ediciones ABYA-YALA, Quito.

Pessar, P. R. y S. J. Mahler 2003. Transnational migration: bringing gender in. International Migration Review 37:812-846.

Phizacklea, A. 1983. One Way Ticket: Migration and Female Labour. Routledge, London.

Pingol, A. 2001. Remaking Masculinities: Identity, Power, and Gender Dynamics in Families with Migrant Wives and Househusbands. UP Center for Women's Studies: Ford Foundation, Quezon City.
Poggio, S. 2000. Migración y cambio en las relaciones de género en las áreas metropolitanas de Washington y Baltimore. En Migración Femenina hacia EUA. Cambio en las Relaciones Familiares y de Género como Resultado de la Migración, editado por S. Poggio y O. Woo, pp. 21-46. EDAMEX, México D.F.

Puyana, Y. 2004. La familia extensa: una estrategia ante crisis sociales y económicas. Trabajo Social 6:77-86.

Revilla, M. y C. Gómez 2012. Caminos de Ida y Vuelta. Redes, Migración y Desarrollo. Catarata, Madrid.

Rivas, A. M. 2008. Mujeres y Hombres en Conflicto. Trabajo, Familia y Desigualdades de Género, Ediciones HOAC, Madrid.

Rivas, A. M. y H. Gonzálvez 2011. El papel de las remesas económicas y sociales en las familias transnacionales. Migraciones Internacionales 6:2-21.

Saltzman, J. 1989. Equidad y Género. Una Teoría Integrada de Estabilidad y Cambio. Cátedra, Madrid.

Sartori, G. 2001. La Sociedad Multiétnica. Pluralismo, Multiculturalismo y Extranjeros. Santillana, Madrid.

Solimano, A. y C. Allendes 2008. Migraciones internacionales, remesas y el desarrollo económico. La experiencia Latinoamericana. En Migraciones Internacionales en América Latina. Booms, Crisis y Desarrollo, editado por A. Solimano, pp. 29-73. FCE, Santiago de Chile.

Tapia, M. 2010. Yo Venía con un Sueño... Relaciones de Género entre Inmigrantes de Origen Boliviano en Madrid. 2000 2007. Tesis para optar al grado de Doctor en América Latina Contemporánea, Instituto Universitario de Investigación José Ortega y Gasset, Universidad Complutense, Madrid.

Tapia, M. 2011a. Género y migración: Trayectorias Investigativas en Iberoamérica. Revista Encrucijada Americana 4 (2):115-147.

. _ _ 2011b. Las relaciones de pareja entre migrantes bolivianos/as en Madrid: ¿Cambios, resistencias o continuidades? AIBR Revista de Antropología Iberoamericana 6 (3):341-371.

Viveros, M. 2001. Masculinidades. Diversidades regionales y cambios generacionales en Colombia. En Hombres e Identidades de Género. Investigaciones desde América Latina, editado por M. Viveros, et al., pp. 37-143. Universidad Nacional de Colombia, Bogotá.

Vogler, C. y J. Pahl 1999. Money, power and inequality. En The Sociology of the Family: A Reader, editado por A. Graham, pp. 129-148. Wiley-Blackwell, Oxford.

Zentgraf, K. 2002. Immigration and women's empowerment: Salvadorans in Los Angeles. Gender Society 16:625-646.

\section{Notas}

1 Este artículo se fundamenta en los resultados de la investigación titulada El papel de las remesas económicas y sociales dentro de las familias migrantes transnacionales financiado en el II Concurso de Proyectos de Investigación de la Red Universitaria de Investigación sobre Cooperación para el Desarrollo, en su convocatoria 2007, de la Red Universitaria de Investigación sobre Cooperación para el Desarrollo del Ayuntamiento de Madrid. El proyecto fue dirigido por la Doctora Ana María Rivas Rivas, Profesora Titular del Departamento de Antropología Social Universidad Complutense de Madrid y estuvo conformado por investigadoras de universidades españolas (Universidad Complutense de Madrid, Universidad Autónoma de Madrid e Instituto Universitario de Investigación Ortega y Gasset) y colombianas (Universidad del Valle y Universidad de Antioquia). El trabajo fue publicado en extenso el año 2009 en Madrid bajo el título 
Familias transnacionales colombianas. Transformaciones y permanencias en las relaciones familiares y de género, editado por Ana María Rivas y Herminia Gonzálvez y publicado por Editorial Catarata.

2 Según los datos del Padrón Municipal publicado por el Instituto Nacional de Estadísticas de España, el año 1996 residían 542.314 extranjeros en el país, lo que representaba el $1,36 \%$ del total de la población empadronada. El año 2008 los extranjeros se multiplicaron en casi 10 veces con un total de 5.268.762, lo que representaba una proporción del 11,4\% del total de empadronados (INE España 2012).

3 De acuerdo a los datos del Padrón Municipal el año 1996 la Comunidad de Madrid contaba con 94.896 extranjeros, lo que representaba el $1,9 \%$ del total de empadronados de esa comunidad. El año 2008 la cifra absoluta de extranjeros se elevó a 1.005.381, lo que representó el 25\% del total de empadronados en la Comunidad de Madrid, situándose en la segunda comunidad con más extranjeros después de Cataluña (INE España 2012). Del total de extranjeros empadronados en Madrid el año 2008, un 47\% eran de origen latinoamericano (Consejería de Inmigración y de Cooperación de Madrid 2008).

4 Colombia se define como Estado Social de Derecho basado en los principios constitucionales de la solidaridad y la redistribución de los ingresos de las personas. De acuerdo a esta definición, desde 1991 el Estado asumió la tarea de clasificar los inmuebles residenciales con el objeto de distribuir los servicios públicos. El objetivo era cobrar de manera diferencial-por estratos- los servicios públicos domiciliarios, lo que permite otorgar subsidios donde es necesario y cobrar contribuciones donde es pertinente. Así quienes tienen más capacidad económica pagan más por los servicios públicos y ayudan a quienes tienen menos recursos a pagar las tarifas. Los estratos en que se clasifican las viviendas y los predios rurales son seis: 1. Bajo-bajo, 2. Bajo, 3. Medio-bajo, 4. Medio, 5. Medio-alto y 6.Alto (DANE 2012).

5 Se entiende por familia monoparental a aquella "Familia encabezada por una sola persona adulta, hombre o mujer, y en la que hay más miembros que dependen económicamente y socialmente de ella" (Sartori 2001: 101).

6 Entendemos por familia extensa aquellas que se conforman por un núcleo familiar (monoparental, nuclear, etc.) y algunos de sus allegados.

7 Las familias nucleares son aquellas familias corrientemente asociadas con el modelo familiar que desde la segunda mitad del siglo XIX se ha convertido en el modelo normativo y hegemónico en las sociedades occidentales (Rivas 2008).

8 En relación con el número de familias, consideramos que el trabajo de campo realizado con nueve familias fue suficiente para analizar el impacto de las remesas económicas en las relaciones de género. Para ello clarificamos que el criterio de selección de los entrevistados/as no fue el de la representación estadística, "en el sentido sociológico convencional". En este caso, el criterio fue el de la representación tipológica socioestructural correspondiente a los objetivos del estudio, garantizando así mínimamente la heterogeneidad de la muestra según las variables consideradas analíticamente relevantes. Nos hemos guiado por los trabajos de Ninna Nyberg Sorensen y Luis E. Guarnizo (2007), quienes llevaron a cabo sus análisis con seis casos, señalando que aunque no son representativos estadísticamente hablando, sí lo son en tanto son "ejemplares" o típicos de procesos más amplios que ocurren como consecuencia de las condiciones migratorias contemporáneas (Nyberg Sorensen y Guarnizo 2007:9). Es pertinente citar otras investigaciones socioantropológicas clásicas como el trabajo de Elisabeth Bott (2008) Familia y red Social en el que a partir de un número "reducido" de casos, se ha realizado un gran aporte al conocimiento y la reflexión en antropología.

9 En este sentido adherimos a las miradas críticas sobre desarrollo que discuten el reduccionismo económico predominante en los análisis sobre migración y remesas y sostenemos la necesidad de incorporar una mirada microsocial en los estudios migratorios en el sentido propuesto por Max-Neef (1992) y Amartya Sen (2000) (Citado en Revilla y Gómez 2012:39-41). Especialmente respecto del uso de las remesas que en muchos casos van a satisfacer necesidades de consumo cotidiano, como educación y salud, dimensiones propias del desarrollo que los estados de origen de los migrantes no logran satisfacer por la baja o escasa cobertura social en previsión, salud, educación y vivienda (Puyana 2004). "El desarrollo así concebido, en su dimensión humano-social, permite distinguir entre libertades y realizaciones concretas, asunto que nos parece central cuando nos acercamos a las condiciones que enfrentan los inmigrantes para hacer uso de su libertad de acción en un marco contextual de posibilidades y oportunidades y limitaciones, pero también en cuanto a sus iniciativas personales" (Revilla y Gómez 2012:41).

$10 \mathrm{http} / / /$ www.businesscol.com/empresarial/tributarios/salario_minimo.htm consultado el 20 de enero de 2011.

11 Según Mejía, para el caso de Bogotá la recepción de las remesas se concentra en jefes de hogar y cónyuges que constituyen el $80 \%$ de los receptores, de ese universo el 68,5\% son mujeres (Mejía et al. 2009:44).

12 En el proceso de regularización del año 2005 se presentaron 690.679 peticiones de las cuales 604.357 fueron admitidas, es decir, el $88 \%$ del total. De ese universo 56.652 peticiones correspondieron a trabajadores migrantes colombianos situándose en cuarto lugar del total de peticiones (Kostova 2006). 
